\title{
Improvement of Live Birth Rate Following Frozen-Thawed Blastocyst Transfer by Combination of Prednisolone Administration and Stimulation of Endometrium Embryo Transfer
}

\author{
Taketo Inoue $^{1,2 *}$, Yoshiyuki Ono¹, Yukiko Yonezawa1, Junji Kishi' ${ }^{1}$, Nobuyuki Emi1 \\ ${ }^{1}$ Ono Ladies Clinic, Ono, Japan \\ ${ }^{2}$ Department of Biophysics, Kobe University Graduate School of Health Sciences, Kobe, Japan \\ Email: taketoein@yahoo.co.jp
}

Received 20 June 2014; revised 18 July 2014; accepted 15 August 2014

Copyright (C) 2014 by authors and Scientific Research Publishing Inc.

This work is licensed under the Creative Commons Attribution International License (CC BY). http://creativecommons.org/licenses/by/4.0/

\section{(c) (i) Open Access}

\section{Abstract}

The endometrial condition is a significant factor for successful pregnancy. To regulate endometrial function in fertility treatment, prednisolone (PSL) is administered for suppression of increased natural killer cells and stimulation of endometrium embryo transfer (SEET) to enhance communication between embryo and maternal tissues. We attempted to improve the endometrial condition by PSL administration and SEET during frozen-thawed blastocyst transfer (FBT). Patients took PSL ( $5 \mathrm{mg}$ ) 3 times daily for 3 days after ovulation during the FBT cycle. To analyse effects of PSL combined with SEET, we determined rates of chemical pregnancy, clinical pregnancy, foetal heart movement (FHM) and live birth. Rates of chemical pregnancy, clinical pregnancy and FHM were significantly higher in the PSL(+)/SEET(+) $(57.7 \%, 50.0 \%$ and $46.2 \%$, respectively) and PSL(+)/SEET(-) (53.3\%, 46.7\% and 46.7\%, respectively) groups than in the PSL(-)/SEET(+) $(30.3 \%$, $18.2 \%$ and $18.2 \%$, respectively) and PSL(-)/SEET $(-)(22.4 \%, 22.4 \%$ and $18.4 \% ; P=0.0043,0.0081$ and 0.0055 , respectively) groups. The live birth rate was significantly higher in the PSL(+)/SEET(+) group than in the PSL(+)/SEET(-), PSL(-)/SEET(+) and PSL(-)/SEET(-) groups $(42.3 \%, 26.7 \%, 18.2 \%$ and $12.2 \%$, respectively; $P=0.0237)$. PSL combined with SEET may be a useful adjunct to assisted reproductive technology in women who repeatedly fail to conceive by infertility treatment.

\section{Keywords}

Frozen-Thawed Blastocyst Transfer, Infertility, Live Birth, Prednisolone, Stimulation of

\footnotetext{
${ }^{*}$ Corresponding author.
} 


\section{Endometrium Embryo Transfer (SEET)}

\section{Introduction}

In 2010, an estimated 48.5 million couples have been reported to be infertile worldwide [1] and $>5$ million children have been born after assisted reproductive technology [2]. For in vitro fertilisation (IVF) and intracytoplasmic sperm injection (ICSI), clinical pregnancy rates per transfer have been reported to be $32.9 \%$ and $32.0 \%$, respectively, and for frozen-thawed embryo transfer, pregnancy rates per thawing have been reported to be $20.9 \%[3]$.

For successful pregnancy, the endometrial condition is important. Accordingly, to regulate endometrial function, infertility patients who have had recurrent spontaneous abortions have been treated with drugs such as prednisolone (PSL) [4]-[6] and aspirin [7]-[9] combined with luteal support. In the endometrium of patients who have had recurrent spontaneous abortions, natural killer (NK) cells are increased [10]. A previous study showed that PSL suppressed NK cell cytotoxicity [11]. Accordingly, several studies have attempted to improve pregnancy rates by administration of PSL in patients after embryo transfer [4]-[6]. However, PSL treatment of fresh embryo derived from ICSI transfer did not improve pregnancy rates [5]. On the other hand, pregnancy rates were successfully improved after fresh embryo transfer by PSL treatment [4] [6]. Moreover, for successful embryo implantation, communication between the developing embryo and maternal tissues (crosstalk) may be important [12]. Previous studies have attempted to induce crosstalk by inserting embryo culture supernatant, which may contain several factors, such as interleukin-1, hCG and vascular endothelial growth factors from pre-implantation embryos, into a patient's uterus before blastocyst transfer [13]-[15]. As a result, pregnancy rates were successfully increased.

We focused on the effect of PSL administration during frozen-thawed blastocyst transfer (FBT) cycle combined with stimulation of endometrium embryo transfer (SEET). However, effects of PSL are still unclear during the FBT cycle. Accordingly, we investigated the effect of PSL combined with SEET on improvement of pregnancy rates during luteal support for FBT.

\section{Materials and Methods}

\subsection{Patients}

A retrospective study was performed on data obtained from 138 FBT cycles between October 2010 and December 2011 [115 ovum pick-up (OPU) cycles]. Informed consent was obtained regarding the dosage of PSL and SEET. All the procedures were performed in accordance with the Declaration of Helsinki.

\subsection{Ovarian Stimulation/in Vitro Fertilisation/Intracytoplasmicsperm Injection}

For ovarian stimulation, the long, short or gonadotropin-releasing hormone antagonist protocols were used depending on the patient. In poor responders, clomifene citrate (50 mg Spacromin tablet; Pola Pharma Inc., Tokyo, Japan) and human menopausal gonadotropin (hMG; ASKA Pharmaceutical Co., Ltd., Tokyo, Japan) were used for ovarian stimulation. GnRH analogue acetate (Fuji Pharma Co., Ltd., Tokyo, Japan), human menopausal gonadotropin and GnRH antagonist (Cetrotide ${ }^{\circledR}$; Shionogi \& Co., Ltd., Osaka, Japan) were used in all protocols. When at least 2 follicles reached $18-20 \mathrm{~mm}$ in diameter (determined by transvaginal ultrasonography), $5000 \mathrm{IU}$ of human chorionic gonadotropin (hCG; Fuji Pharma) was administered. OPU was performed $35 \mathrm{~h}$ after hCG injection. Oocytes were inseminated by IVF or ICSI. ICSI was performed as described previously [16]. In brief, spermatozoa were selected by hyaluronic acid (HA). HA-bound spermatozoa were injected into oocytes using a piezo micro manipulator (Prime Tech Ltd., Ibaraki, Japan). Fertilised eggs were cultured in Single Step Medium $^{\mathrm{TM}}$ (Irvine Scientific, Santa Ana, CA, USA) with 10\% Serum Substitute Supplement (Irvine Scientific) until Day 5. Two morphological blastocyst categories were defined according to the criteria of Gardner et al. [17]. Grades 3AA, 4AA, 4AB, 4BA, 5AA, 5AB, 5BA, 6AA, 6AB and 6BA were categorised as high-grade blastocysts, and the others were categorised as low-grade blastocysts [15]. 


\subsection{Cryopreservation/Thawing/Blastocyst Transfer}

Blastocysts were cryopreserved and thawed using the Cryotop technique, as described previously [18], with the modification that thawing was performed at room temperature. A frozen-thawed blastocyst was transferred to a uterus. During luteal support for FBT cycles, patients were administered $2 \mathrm{mg}$ of chlormadinone acetate (Lutoral; Shionogi \& Co., Ltd.) 3 times daily after ovulation, and $0.72 \mathrm{mg}$ transdermal estradiol patches (Estrana ${ }^{\circledR}$ Tape; Hisamitsu Pharmaceutical Co., Inc., Tokyo, Japan) were applied on the abdomen for 10 weeks after the initiation of menstruation. On the day of blastocyst transfer, if serum progesterone concentration was $<15 \mathrm{ng} / \mathrm{ml}$, the women were injected with $125 \mathrm{mg}$ of $17 \alpha$-hydroxyprogesterone caproate once every 5 days [19]. Patients took 5 mg of PSL (prednisolone tablet; Towa Pharmaceutical Co., Ltd., Osaka, Japan), 3 times daily for 3 days after ovulation. The dosage of PSL was set at $15 \mathrm{mg} /$ day based on previous references [6]. SEET [13] [14] was performed 2 or 3 days before FBT.

\subsection{Statistical Analysis}

The average patient age, OPU frequency and number of motile spermatozoa were evaluated using one-factor analysis of variance. These data are presented as means \pm standard deviations (SDs). Ratios of blastocysts derived from IVF/ICSI and blastocyst grade and rates of chemical pregnancy, clinical pregnancy, foetal heart movement (FHM) and live birth were evaluated using chi-square test and residual analysis. A probability level of $P<0.05$ was considered to indicate statistical significance.

\section{Results}

To investigate the effect of PSL combined with SEET during luteal support for FBT, we confirmed rates of chemical pregnancy, clinical pregnancy, FHM and live birth. No significant differences were observed in backgrounds of patients (average patient age, OPU frequency and number of motile spermatozoa) and characteristics of blastocysts (rates of fertilisation and development, ratio of blastocysts derived from IVF/ICSI and ratio of high to low-grade blastocysts) among all groups (Table 1). Rates of chemical pregnancy, clinical pregnancy and FHM were significantly higher in the PSL $(+) /$ SEET $(+)$ and PSL $(+) / \operatorname{SEET}(-)$ groups than in the PSL $(-) / \operatorname{SEET}(+)$ and PSL $(-) /$ SEET $(-)$ groups $(P=0.0043,0.0081$ and 0.0055 , respectively; Table 1$)$. Furthermore, the live birth rate was significantly higher in the PSL $(+) / \operatorname{SEET}(+)$ group than in the PSL $(+) / \operatorname{SEET}(-), \operatorname{PSL}(-) / \operatorname{SEET}(+)$ and $\operatorname{PSL}(-) / \operatorname{SEET}(-)$ groups $(P=0.0237$; Table 1$)$.

Table 1. Effect of prednisolone combined with SEET during frozen-thawed blastocyst transfer cycle.

\begin{tabular}{|c|c|c|c|c|c|}
\hline & $\operatorname{PSL}(+) / \operatorname{SEET}(+)$ & $\operatorname{PSL}(+) / \operatorname{SEET}(-)$ & $\operatorname{PSL}(-) / \operatorname{SEET}(+)$ & $\operatorname{PSL}(-) / \operatorname{SEET}(-)$ & $P$ value \\
\hline Age of women & $33.0 \pm 5.0$ & $35.4 \pm 4.5$ & $35.3 \pm 4.4$ & $32.8 \pm 5.4$ & 0.0676 \\
\hline No. of ovum pick-up cycles & 23 & 25 & 30 & 37 & \\
\hline Ovum pick-up frequency & $2.5 \pm 2.5$ & $2.3 \pm 1.5$ & $2.8 \pm 1.6$ & $2.5 \pm 2.7$ & 0.9090 \\
\hline No. of motile spermatozoa $\left(\times 10^{6} / \mathrm{ml}\right)$ & $53.1 \pm 45.7$ & $62.5 \pm 35.4$ & $46.4 \pm 36.0$ & $40.9 \pm 34.6$ & 0.1837 \\
\hline No. of recovered oocytes & 171 & 216 & 186 & 295 & \\
\hline No. of 2PN2PB oocytes & $(64.3 \%)$ & $(71.3 \%)$ & $(71.5 \%)$ & $(72.5 \%)$ & 0.2761 \\
\hline No. of blastocysts & $(61.8 \%)$ & $(61.7 \%)$ & $(63.2 \%)$ & $(59.3 \%)$ & 0.9060 \\
\hline No. of blastocyst transfers & 26 & 30 & 33 & 49 & \\
\hline Blastocysts derived from IVF/ICSI & $12 / 14$ & $20 / 10$ & $19 / 14$ & $26 / 23$ & 0.4560 \\
\hline Ratio of high- to low-grade blastocysts & $14 / 12$ & $15 / 15$ & $18 / 15$ & $21 / 28$ & 0.7060 \\
\hline No. of chemical pregnancies & $(57.7 \%)^{*}$ & $(53.3 \%)^{*}$ & $(30.3 \%)$ & $(22.4 \%)^{* *}$ & 0.0043 \\
\hline No. of clinical pregnancies & $(50.0 \%)^{*}$ & $(46.7 \%)^{*}$ & $(18.2 \%)$ & $(22.4 \%)$ & 0.0081 \\
\hline No. of foetal heart movement & $(46.2 \%)^{*}$ & $(46.7 \%)^{*}$ & $(18.2 \%)$ & $(18.4 \%)$ & 0.0055 \\
\hline No. of live births & $(42.3 \%)^{* *}$ & $(26.7 \%)$ & $(18.2 \%)$ & $(12.2 \%)^{*}$ & 0.0237 \\
\hline
\end{tabular}

PN, pronucleus; PB, polar body. Significant difference between each group at $P<0.05$ using chi-square test and residual analysis. ${ }^{*}: P<0.05$, **: $P$ $<0.01$. 
No adverse effects of PSL were observed. In all successful pregnancies, all mothers and babies were healthy.

\section{Discussion}

The present study showed that pregnancy rates were successfully improved by PSL administration, and the live birth rate was successfully and significantly increased by PSL combined with SEET during the FBT cycle. Several studies have attempted to administer PSL to patients during fresh embryo transfer cycles [4]-[6]. PSL treatment of fresh embryos derived from ICSI transfer did not improve pregnancy and implantation rates (PSL vs. control; $49.0 \%$ vs. $50.0 \%$ and $23.6 \%$ vs. $23.3 \%$, respectively [5]). On the other hand, pregnancy rates were successfully improved by PSL treatment after fresh embryo transfer in patients with auto-antibodies [4] [6]. Hasegawa et al. [4] reported that administration of PSL and low-dose aspirin therapy to women with positive antinuclear antibodies but without anti-phospholipid antibodies significantly improved pregnancy and implantation rates ( $40.6 \%$ vs. $14.8 \%$ and $20.3 \%$ vs. $6.8 \%$, respectively). Taniguchi [6] showed that implantation (12.2\% vs. $0 \%$ ) and clinical pregnancy (29.3\% vs. $0 \%$ ) rates were improved by PSL administration; however, the live birth rate was not (14.6\% vs. $0 \%)$. In the present study, rates of clinical pregnancy and FHM were improved by administration of PSL during FBT cycles. In addition, our results showed that the live birth rate did not improve during FBT cycles by PSL alone.

Tehraninejad et al. [15] reported that term deliveries increased and abortions decreased by stimulation of the endometrium with high-grade blastocyst culture supernatant perfusion before fresh blastocyst transfer. Considering these results, we attempted to improve the live birth rate during FBT cycles by administering the combination of PSL and SEET to enhance crosstalk. Our study showed that the live birth rate was successfully and significantly increased by the combination of PSL and SEET during the FBT cycle $(P=0.0237)$. A comparison between PSL $(-) /$ SEET $(+)$ and PSL $(-) / S E E T(-)$ groups revealed no obvious differences in rates of clinical pregnancy, in contrast to the results of a previous study [14]. Goto et al. [14] reported that SEET may be an effective method for increasing implantation and pregnancy rates (SEET, 80.0\%; blastocyst transfer, 56.0\%) in patients receiving assisted reproductive technology treatment for the first time who had high-grade blastocysts (pregnancy rates of low-grade blastocysts; SEET, 39.1\%; blastocyst transfer, 52.2\%). Moreover, in contrast to the results of the previous study by Tehraninejad et al. [15], the live birth rate did not improve by SEET. In this study, ratios of low-grade to high-grade blastocysts were approximately half the number of blastocysts derived from IVF/ICSI in each group. Accordingly, our results suggested that SEET alone was not efficacious during FBT involving low-grade blastocysts.

In the present study, although ratios of low-grade blastocysts were approximately half the number in each group, the live birth rate was successfully improved by the combination of PSL and SEET during the FBT cycle. For early normal pregnancy, uterine CD56 ${ }^{\text {bright }} \mathrm{NK}$ cells are necessary, probably because they secrete both proand anti-inflammatory cytokines in relative proportions that determine the degree of inflammation at the fetomaternal interface [20]. On the other hand, in women with a history of recurrent miscarriage [20] and recurrent failed implantation [21] [22], uterine NK (uNK) cells were found to be increased in their endometrium. Elevated uNK cell density has been shown to be associated with lower endometrial expression of $11 \beta$-hydroxysteroid dehydrogenase type 1 and mineralocorticoid receptor [23]. Moreover, expression of mineralocorticoid receptor-dependent genes, such as dehydrogenases/reductase superfamily 3 and retinol saturase that are involved in lipid metabolism and retinoid acid biosynthesis and storage, decreased [23]. Accordingly, we speculated that by supplementing the decreased corticoids via PSL treatment, lipid metabolism [24] and retinoid acid biosynthesis/storage [25] [26], which are essential for embryogenesis and maintenance of pregnancy, could be improved. Consequently, the live birth rate was successfully increased in the present study.

Moreover, PSL treatment modified the endometrial environment for embryogenesis and maintenance of pregnancy through reduction of the numbers of endometrial macrophages and uNKs [27] [28], which suppressed the cytolytic activity of NK cells [11] and associated highly muscularised vessels [28]. The present study showed that the combination of PSL and SEET may be a useful adjunct to assisted reproductive technology in women who repeatedly fail to conceive by infertility treatment.

\section{References}

[1] Mascarenhas, M.N., Flaxman, S.R., Boerma, T., Vanderpoel, S. and Stevens, G.A. (2012) National, Regional, and Global Trends in Infertility Prevalence since 1990: A Systematic Analysis of 277 Health Surveys. PLoS Medicine, 9, 
e1001356.

[2] Pinborg, A., Henningsen, A.A., Loft, A., Malchau, S.S., Forman, J. and Andersen, A.N. (2014) Large Baby Syndrome in Singletons Born after Frozen Embryo Transfer (FET): Is It Due to Maternal Factors or the Cryotechnique? Human Reproduction, 29, 618-627. http://dx.doi.org/10.1093/humrep/det440

[3] Ferraretti, A.P., Goossens, V., Kupka, M., Bhattacharya, S., De Mouzon, J., Castilla, J.A., Erb, K., Korsak, V. and Nyboe Andersen, A.; European IVF-Monitoring (EIM) Consortium for the European Society of Human Reproduction and Embryology (ESHRE) (2013) Assisted Reproductive Technology in Europe, 2009: Results Generated from European Registers by ESHRE. Human Reproduction, 28, 2318-2331. http://dx.doi.org/10.1093/humrep/det278

[4] Hasegawa, I., Yamanoto, Y., Suzuki, M., Murakawa, H., Kurabayashi, T., Takakuwa, K. and Tanaka, K. (1998) Prednisolone plus Low-Dose Aspirin Improves the Implantation Rate in Women with Autoimmune Conditions Who Are Undergoing in Vitro Fertilization. Fertility and Sterility, 70, 1044-1048. http://dx.doi.org/10.1016/S0015-0282(98)00343-4

[5] Ubaldi, F., Rienzi, L., Ferrero, S., Anniballo, R., Iacobelli, M., Cobellis, L. and Greco, E. (2002) Low Dose Prednisolone Administration in Routine ICSI Patients Does Not Improve Pregnancy and Implantation Rates. Human Reproduction, 17, 1544-1547. http://dx.doi.org/10.1093/humrep/17.6.1544

[6] Taniguchi, F. (2005) Results of Prednisolone Given to Improve the Outcome of in Vitro Fertilization-Embryo Transfer in Women with Antinuclear Antibodies. The Journal of Reproductive Medicine, 50, 383-388.

[7] Haapsamo, M., Martikainen, H., Tinkanen, H., Heinonen, S., Nuojua-Huttunen, S. and Räsänen, J. (2010) Low-Dose Aspirin Therapy and Hypertensive Pregnancy Complications in Unselected IVF and ICSI Patients: A Randomized, Placebo-Controlled, Double-Blind Study. Human Reproduction, 25, 2972-2977.

http://dx.doi.org/10.1093/humrep/deq286

[8] Gelbaya, T.A., Kyrgiou, M., Li, T.C., Stern, C. and Nardo, L.G. (2007) Low-Dose Aspirin for in Vitro Fertilization: A Systematic Review and Meta-Analysis. Human Reproduction Update, 13, 357-364. http://dx.doi.org/10.1093/humupd/dmm005

[9] Akhtar, M.A., Eljabu, H., Hopkisson, J., Raine-Fenning, N., Quenby, S. and Jayaprakasan, K. (2013) Aspirin and Heparin as Adjuvants during IVF Do Not Improve Live Birth Rates in Unexplained Implantation Failure. Reproductive BioMedicine Online, 26, 586-594. http://dx.doi.org/10.1016/j.rbmo.2013.02.007

[10] Clifford, K., Flanagan, A.M. and Regan, L. (1999) Endometrial CD56+ Natural Killer Cells in Women with Recurrent Miscarriage: A Histomorphometric Study. Human Reproduction, 14, 2727-2730. http://dx.doi.org/10.1093/humrep/14.11.2727

[11] Thum, M.Y., Bhaskaran, S., Abdalla, H.I., Ford, B., Sumar, N. and Bansal, A. (2008) Prednisolone Suppresses NK Cell Cytotoxicity in Vitro in Women with a History of Infertility and Elevated NK Cell Cytotoxicity. American Journal of Reproductive Immunology, 59, 259-265. http://dx.doi.org/10.1111/j.1600-0897.2007.00574.x

[12] Simón, C., Dominguez, F., Remohí, J. and Pellicer, A. (2001) Embryo Effects in Human Implantation: Embryonic Regulation of Endometrial Molecules in Human Implantation. Annals New York Academy of Sciences, 943, 1-16. http://dx.doi.org/10.1111/j.1749-6632.2001.tb03785.x

[13] Goto, S., Kadowaki, T., Hashimoto, H., Kokeguchi, S. and Shiotani, M. (2007) Stimulation of Endometrium Embryo Transfer (SEET): Injection of Embryo Culture Supernatant into the Uterine Cavity before Blastocyst Transfer Can Improve Implantation and Pregnancy Rates. Fertility and Sterility, 88, 1339-1343. http://dx.doi.org/10.1016/j.fertnstert.2007.01.011

[14] Goto, S., Kadowaki, T., Hashimoto, H., Kokeguchi, S. and Shiotani, M. (2009) Stimulation of Endometrium Embryo Transfer Can Improve Implantation and Pregnancy Rates for Patients Undergoing Assisted Reproductive Technology for the First Time with a High-Grade Blastocyst. Fertility and Sterility, 92, 1264-1268. http://dx.doi.org/10.1016/j.fertnstert.2008.08.076

[15] Tehraninejad, E.S., Tanha, F.D., Ghajarzadeh, M., Zandieh, Z., Aziminekoo, E. and Zanjani, H.R. (2012) Stimulation of the Endometrium with High-Grade Blastocyst Culture Supernatant (SEHB) Can Improve Pregnancy Outcome for Couples Undergoing Intracytoplasmic Sperm Injection (ICSI): A Randomized Clinical Trial. Archives of Gynecology and Obstetrics, 285, 1167-1171. http://dx.doi.org/10.1007/s00404-011-2143-Z

[16] Inoue, T., Ono, Y., Yonezawa, Y., Oi, M., Kobayashi, N., Kishi, J. and Emi, N. (2013) Oocyte Quality Improvement Using a Herbal Medicine Comprising 7 Crude Drugs. Open Journal of Obstetrics and Gynecology, 3, 195-202.

http://dx.doi.org/10.4236/ojog.2013.31A036

[17] Gardner, D.K. and Schoolcraft, W.B. (1999) In Vitro Culture of Human Blastocyst. In: Jansen, R. and Mortimer, D., Eds., Towards Reproductive Certainty: Infertility and Genetics Beyond, Parthenon Press, Carnforth, 377-388.

[18] Kuwayama, M. (2007) Highly Efficient Vitrification for Cryopreservation of Human Oocytes and Embryos: The Cryotop Method. Theriogenology, 67, 73-80. http://dx.doi.org/10.1016/j.theriogenology.2006.09.014 
[19] Inoue, T., Ono, Y. and Emi, N. (2012) Preservation of Spermatozoa by Refrigeration. In: Frias, T.A. and Cano, M.J., Eds., Pregnancy: Risk Factors, Management and Recovery, Nova Science Publishers, Inc., New York, 121-146.

[20] Christiansen, O.B., Nielsen, H.S. and Kolte, A.M. (2006) Future Directions of Failed Implantation and Recurrent Miscarriage Research. Reproducive BioMedicine Online, 13, 71-83.

[21] Tuckerman, E., Mariee, N., Prakash, A., Li, T.C. and Laird, S. (2010) Uterine Natural Killer Cells in Peri-Implantation Endometrium from Women with Repeated Implantation Failure after IVF. Journal of Reproductive Immunology, 87, 60-66. http://dx.doi.org/10.1016/j.jri.2010.07.001

[22] Miko, E., Manfai, Z., Meggyes, M., Barakonyi, A., Wilhelm, F., Varnagy, A., Bodis, J., Illes, Z., Szekeres-Bartho, J. and Szereday, L. (2010) Possible Role of Natural Killer and Natural Killer T-Like Cells in Implantation Failure after IVF. Reproductive BioMedicine Online, 21, 750-756. http://dx.doi.org/10.1016/j.rbmo.2010.07.012

[23] Kuroda, K., Venkatakrishnan, R., James, S., Šucurovic, S., Mulac-Jericevic, B., Lucas, E.S., Takeda, S., Shmygol, A., Brosens, J.J. and Quenby, S. (2013) Elevated Periimplantation Uterine Natural Killer Cell Density in Human Endometrium Is Associated with Impaired Corticosteroid Signaling in Decidualizing Stromal Cells. The Journal of Clinical Endocrinology and Metabolism, 98, 4429-4437. http://dx.doi.org/10.1210/jc.2013-1977

[24] Wang, H. and Dey, S.K. (2005) Lipid Signaling in Embryo Implantation. Prostaglandins and other Lipid Mediators, 77, 84-102.

[25] Xia, H.F., Ma, J.J., Sun, J., Yang, Y. and Peng, J.P. (2010) Retinoic Acid Metabolizing Enzyme CYP26A1 Is Implicated in Rat Embryo Implantation. Human Reproduction, 25, 2985-2998. http://dx.doi.org/10.1093/humrep/deq268

[26] Niederreither, K. and Dollé, P. (2008) Retinoic Acid in Development: Towards an Integrated View. Nature Reviews Genetics, 9, 541-553. http://dx.doi.org/10.1038/nrg2340

[27] Quenby, S., Kalumbi, C., Bates, M., Farquharson, R. and Vince, G. (2005) Prednisolone Reduces Preconceptual Endometrial Natural Killer Cells in Women with Recurrent Miscarriage. Fertility and Sterility, 84, 980-984. http://dx.doi.org/10.1016/j.fertnstert.2005.05.012

[28] Lash, G.E., Bulmer, J.N., Innes, B.A., Drury, J.A., Robson, S.C. and Quenby, S. (2011) Prednisolone Treatment Reduces Endometrial Spiral Artery Development in Women with Recurrent Miscarriage. Angiogenesis, 14, 523-532. http://dx.doi.org/10.1007/s10456-011-9237-x 
Scientific Research Publishing (SCIRP) is one of the largest Open Access journal publishers. It is currently publishing more than 200 open access, online, peer-reviewed journals covering a wide range of academic disciplines. SCIRP serves the worldwide academic communities and contributes to the progress and application of science with its publication.

Other selected journals from SCIRP are listed as below. Submit your manuscript to us via either submit@scirp.org or Online Submission Portal.
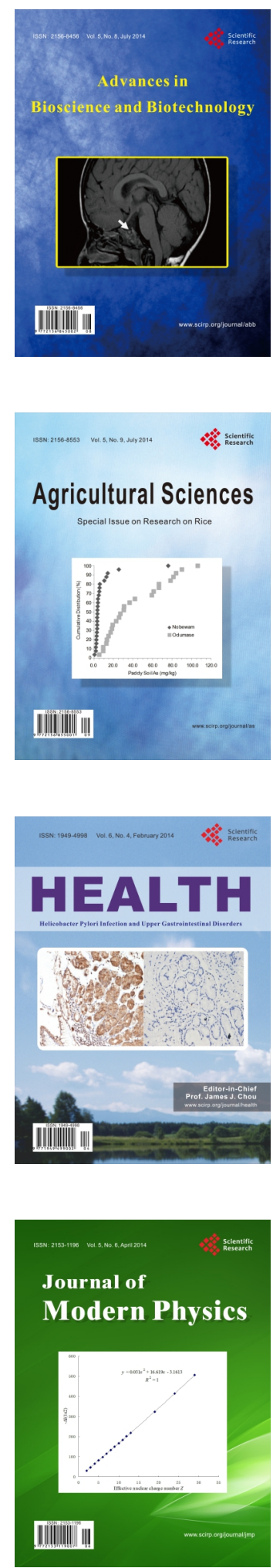
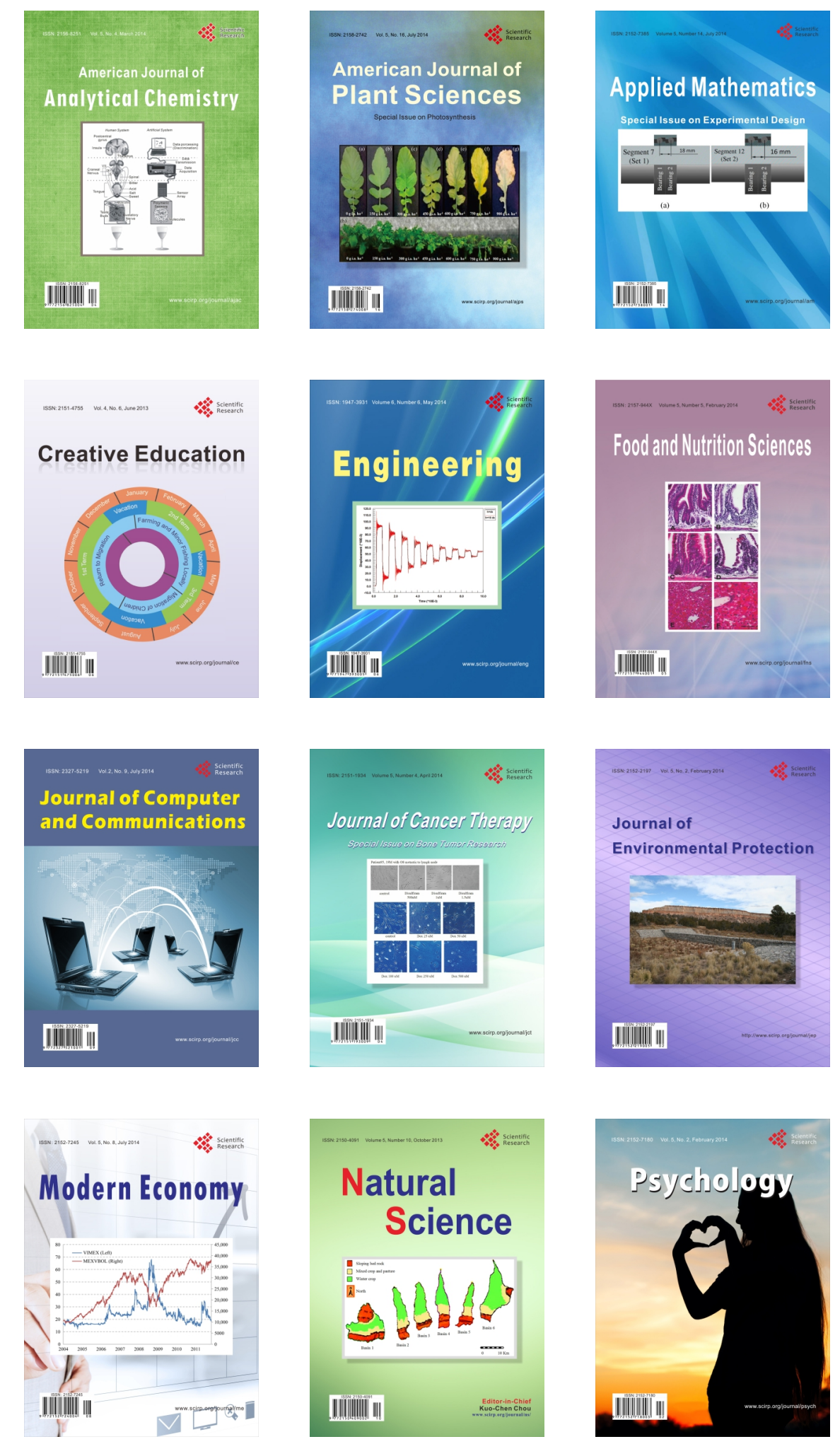